\section{Nobels: Toll pioneers deserve recognition}

Immunologists are delighted that the field of innate immunity has been recognized by this year's Nobel Prize in Physiology or Medicine. However, we believe that the Nobel Committee should also have acknowledged the seminal contributions of immunologists Charles A. Janeway Jr (19432003) and Ruslan Medzhitov.

Janeway laid out the major theory that unifies the principles of innate and adaptive immunity (C. A. Janeway Cold Spring Harb. Symp. Quant. Biol. 54, 1-13; 1989), later experimentally verified with Medzhitov and then by many others. He recognized that antigen alone is insufficient to elicit an adaptive immune response, and postulated that both primitive and higher animals have specialized 'pattern-recognition receptors' that induce the innate immune response when activated by a particular class of conserved microbial products ('pathogenassociated molecular patterns')

The most important tenet of his theory was the connection between innate immune signalling and initiation of the adaptive immune response through enhancement of antigen processing and presentation, induction of co-stimulatory signals and cytokine release.

Medzhitov and Janeway subsequently cloned a human 'Toll-like' receptor and showed that it activated signalling pathways that induce adaptive immunity (R. Medzhitov et al. Nature 388, 394; 1997). This remarkable demonstration also provided a framework for interpreting the significance of Toll-like receptors and their ligands for the immune response.

The innate-adaptive connection is now a fundamental principle in immunology. We believe that the work of Janeway and Medzhitov was a Nobelstandard breakthrough for immunology.

James P. Allison Howard Hughes Medical Institute, Memorial Sloan-Kettering Cancer Center, New York, USA.

Christophe Benoist Harvard

Medical School, Boston,

Massachusetts, USA.

Alexander V. Chervonsky ${ }^{\star}$

University of Chicago, Illinois, USA.

achervon@bsd.uchicago.edu

${ }^{*}$ On behalf of 23 co-signatories

listed alphabetically at http://

dx.doi.org/10.1038/479178a.

\section{Nobels: maintaining Israel's record}

Israeli science has done well in the past decade of Nobel prize awards, with five nominations to three leading institutions or 0.77 laureates per million people (compared with 0.2 for the United States, for example). This is despite the country's tiny population and the fact that it is the world's leading exporter of brainpower. But more investment in education and research will be necessary to maintain this impressive record.

One-quarter of Israel's academic scholars work at leading academic institutions in the United States - five times more than from any other nation apart from Canada (just over $12 \%$; see go.nature.com/ xe9nws).

Since 1973, the proportion of scientists in the population and the government's investment in academia relative to gross domestic product have both dropped by more than half, putting Israel below the average for countries within the Organisation for Economic Co-operation and Development (see go.nature.com/vozgwh).

Another problem is that the ultra-orthodox education system - which is responsible for more than one-quarter of Israel's firstgraders (from age six) - does not teach science or mathematics.

But there is hope for the

future. As shown by the ongoing demonstrations for social justice, one of which was estimated to involve $7 \%$ of Israel's Jewish population, activism is already leading to short- and long-term changes, including a drive for more investment at all levels of education.

Ilan Samish Weizmann Institute of Science, Rehovot, Israel. ilan.samish@weizmann.ac.il

\section{Nobels: fundamental biology misses out}

In 1895, Alfred Nobel

bequeathed much of his immense fortune to create the five original Nobel prizes for literature, physiology or medicine, physics, chemistry, and peace. The award categories were expanded to include economics in 1968, following a large donation to the Nobel Foundation on behalf of the Swedish central bank, by the creation of the Sveriges Riksbank Prize in Economic Sciences in Memory of Alfred Nobel.

The symbolic recognition of the work of Nobel laureates increases awareness of scientific research in the eyes of the public. It is a continuing shame that fundamental biology - and not just its application in medicine - lacks such a patron. P. William Hughes Carleton University, Ottawa, Canada. whughes@connect.carleton.ca

\section{Tropical forests: still vital when degraded}

Luke Gibson et al. argue that tropical conservation efforts should focus on primary and selectively logged forests, because these are the most diverse (Nature 478, 378-381; 2011). However, working in degraded habitats can also provide important conservation opportunities.
Worldwide, around 500,000 hectares of logged and secondary forests are converted every year to plantations such as oil palm, rubber, Acacia and Eucalyptus, reducing both their current biodiversity value and their capacity for regeneration. Because of the revenue they generate, conserving such forests may be more economically viable than the total protection of pristine forests.

Disturbed forests include important 'matrix habitats' between areas of intact forest that can buffer against the impact of habitat fragmentation on reserves. Species occupancy of protected areas is more strongly associated with the condition of the matrix than with either reserve size or isolation (L. R. Prugh et al. Proc. Natl Acad. Sci. USA 105, 20770 $20775 ; 2008)$. Such forests also provide crucial habitat for wideranging species.

In many parts of the tropics, primary forests are confined to upland areas or to poor soils, and are biogeographically restricted. It may be more productive to focus on restoring degraded, but endangered, lowland habitats than on protecting yet more upland forest.

Another consideration is that hunting in tropical reserves significantly threatens their long-term viability. Protection of wildlife may be better achieved through working with timber or oil concessions, or in buffer-zone tourist reserves, than with cash-strapped (or otherwise compromised) nature-reserve agencies.

Tropical reserves cover roughly $11 \%$ of the tropicalforest biome, whereas $40 \%$ is deforested, $20 \%$ is logged and an unknown but significant proportion of the remainder is severely degraded (S. J. Wright Annals New York Acad. Sci. 1195, 1-27; 2010). Such figures alone make it necessary to consider the protection of biodiversity in 
degraded tropical habitats.

Rhett D. Harrison

Xishunagbanna Tropical

Botanical Garden, Chinese

Academy of Science, Menglun,

Yunnan, China.

rharrison@xtbg.org.cn

\section{Tropical forests: try holistic conservation}

Sustaining tropical biodiversity in the long term requires more than just protection of remaining primary forests (L. Gibson et al. Nature 478, 378-381; 2011). It is essential to encourage landuse strategies that increase the potential conservation value of habitats modified by humans. Substantial tropical biodiversity can also thrive in such humandominated ecosystems.

Luke Gibson and colleagues highlight the importance of disappearing forests by comparing biodiversity in tropical primary forests with corresponding human-modified habitats. But clinging to the ecological ideal excludes equally important comparisons to ecological dystopias. For example, when I re-analysed the data to include a 'degraded' reference state with poor biodiversity (see www. stanford.edu/ cdm/Pubs/SOM), it revealed that human-dominated ecosystems sustain at least a medium amount of biodiversity. This is substantial, considering that such ecosystems constitute roughly $85 \%$ of the tropics (E. C. Ellis et al. Global Ecol. Biogeogr. 19, 589-606; 2010).

Rather than championing conservation of primary forest over land-use strategies favouring conservation, we must develop a holistic conservation model that includes humandominated ecosystems. Chase D. Mendenhall Center for Conservation Biology, Stanford University, California, USA. cdm@stanford.edu

\section{Tropical forests: include Congo basin}

Luke Gibson and co-workers provide an important global assessment of the impact of disturbance and land conversion

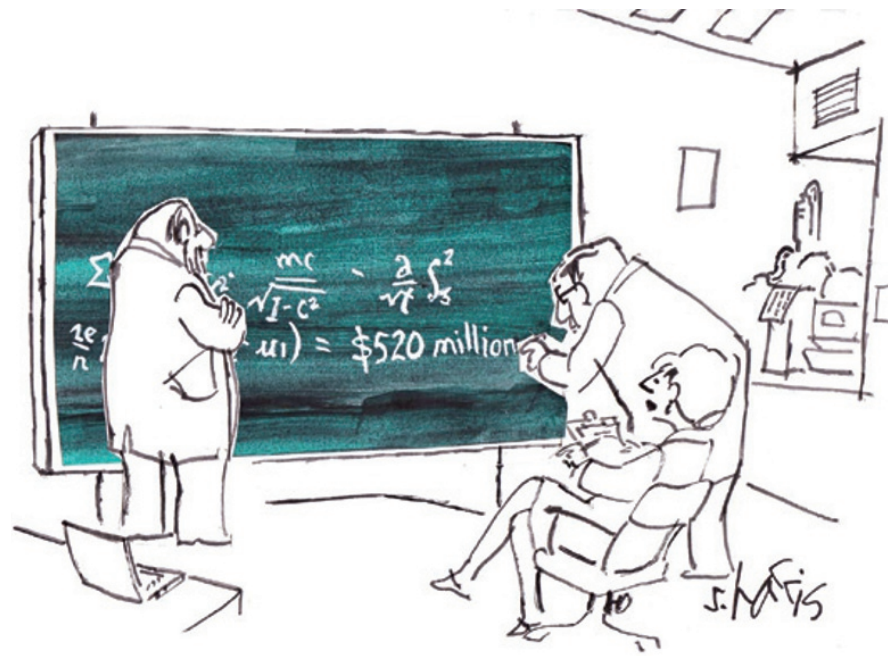

on biodiversity in tropical forests (Nature 478, 378-381; 2011). But their meta-analysis of 138 studies overlooks the Congo basin, the second-largest continuous area of rainforest in the world; moreover, only 12 studies are located in Africa. This omission is not the fault of the authors, but is symptomatic of the lack of recent and accessible legacy data for this region.

The Democratic Republic of Congo (DRC), which contains 98 million hectares of rainforest (60\% of the Congo basin forest), is also poorly represented in studies beyond biodiversity. Take, for example, a study that estimates the carbon sink in the world's forests on the basis of inventory data and long-term ecosystem studies (Y. Pan et al. Science 333, 988-993; 2011). The study's estimate for carbon stocks in intact tropical forest across Africa is based on a network of 79 monitoring sites, yet only ten of these are in the DRC, all in the same forest reserve in the northeastern Ituri province.

Large scientific, logistic and training efforts are needed to establish permanent monitoring sites in the Congo basin's tropical forests and woodlands, and to connect those sites to global networks.

Countries such as the DRC must also identify and monitor forest biodiversity and carbon stocks within the framework of international climate and conservation policies, such as the United Nations REDD programme (for 'reducing emissions from deforestation and forest degradation'). This will help to preserve the Congo basin forest, where deforestation so far remains modest compared with that in the Amazon region and in southeast Asia.

Hans Verbeeck, Pascal Boeckx, Kathy Steppe Ghent University, Belgium.

hans.verbeeck@ugent.be

\section{Clarifying the use of 'prepubescent'}

By implying that 11- and 12-year-old girls are "prepubescent", you play into the hands of those who oppose vaccinating young girls against human papilloma virus (HPV) to prevent cervical cancer (Nature 477, 369; 2011).

Although the average age of first menstruation (menarche) was 12.8 years in the United States in 1968 , this is becoming steadily younger (see, for example,

S. E. Anderson and A. Must J. Pediatr. 147, 753-760; 2005). Also, as menarche comes quite late in a girl's progress towards full adult height and reproductive capacity, girls should no longer be described as prepubescent at ages 11 and 12 .

A case could be made for scheduling vaccination against $\mathrm{HPV}$ at an even younger age - at the start of breast development, or around age 10 , before a girl is likely to become sexually active.

Evelyn J. Bowers Ball State

University, Muncie, Indiana,

USA.

o0ejbowers@bsu.edu

\section{More than one fund for US entrepreneurs}

There are more funding opportunities for entrepreneurial US scientists than Steve Blank conveys (Nature 477, 133; 2011). These are especially pertinent in a year when the National Science Foundation (NSF) is seeking congressional reauthorization for its Small Business

Innovation Research (SBIR) Program.

Although the NSF's US\$5-million Innovation Corps (I-Corps) initiative is welcome, the SBIR Program has available funds of about $\$ 150$ million a year. Overall, SBIR programmes at the NSF, NASA and the US government departments of energy, defence and commerce provide $\$ 2$ billion in funding a year. Since their inception in 1982, they have enabled a whole generation of scientists to become entrepreneurs.

The I-Corps sends funding directly to universities rather than to small businesses. However, many SBIR-funded small businesses were originally university spinoffs, and the complementary Small Business Technology Transfer (STTR) programme already targets partnerships between universities and small businesses.

Probably the most innovative element of the I-Corps programme is its partial funding by private foundations. If this could be increased, it would help to alleviate pressure on federal funding of the SBIR and STTR programmes.

SBIR funding was significant to the success of both of the science-entrepreneurial spin-offs in which I was involved after leaving Harvard University (see www.aer.com and www.cri-inc.com). These companies have since gone public, having generated products for worldwide use in applications ranging from biomedical imaging to environmental control.

Peter Foukal Nahant, Massachusetts, USA. pvfoukal@comcast.net 